\title{
FONTS FOR IMPROVEMENT OF THE READING ABILITIES IN PERSONS WITH DYSLEXIA
}

\begin{abstract}
This paper reflects on the features of current fonts created for persons with dyslexia. First, it addresses the explanation of reading, as an affected ability in the persons with dyslexia, then it suggests a description of dyslexia as the most common learning difficulty and points out the key theories for its origin, as well as the basic deficits that occur in these persons and put a strain on the reading process. This interpretation of the basic terminology is followed by a comparative analysis of the researches related to the fonts for dyslexia, as an introduction to the essential features of these fonts. The font features are explained in the third part of the paper. In it, general features of fonts are clarified, and afterwards it is stated how these features vary in the fonts for dyslexic readers, in order for them to be adjusted to their needs. Though a comparison between the best known Latin fonts is made, there is a description of a font created with the same purpose, but for the Cyrillic script.
\end{abstract}

Key words: FONT, DYSLEXIA, READING, MAGNOCELLULAR THEORY

\section{Theoretical bases of the research subject}

\section{Reading}

Reading is a skill of decoding written symbols, but also a skill that penetrates in the meaning behind those symbols. It bears a fundamental meaning for the development of critical and imaginative thinking in children, as well as their intellectual and emotional development. The reading process entails three systems that complement each other: a graphic system-the reader reacts to the series of graphemes and links them to the mother tongue system; a syntax system-entails deep structural analysis and a semantic system-which covers conceptualization and experience besides the meaning. There are a number of views regarding the basic skills that are important for accurate and fluent reading. The important factors found in all authors that work in this field are word learning skills (such as: letter recognition, segmentation, blending, phonemic awareness, analogy strategies and grapheme-phoneme correspondence) and word recognition skills (like word scheme recognition and visual memory skills). Success in reading includes gaining competencies in two separate, but complementary processes: word identification (decoding) and their linguistic comprehension. In order for a student to become a successful reader, he/she should learn effective strategies for iden- 
tification of all words, as well as for text comprehension. Literacy instructions should be consisted of concrete teaching and practices with the purpose to enable all students to read fluently, self-confidently and with understanding (Westwood, 14).

\section{Dyslexia}

Writing and reading are not birth given skills and therefore teaching must be explicit. Dyslexia is a type of learning difficulty that influences one's ability to read. Confusion and mixing of words, letters and numbers that look alike is common in children during the process of learning of the symbols used for writing and math and this is a developmentally normal occurrence in children learning to read. However, for many dyslexic children this is a developmental problem related to their reading level. For some dyslexic children this problem lasts much longer. Dyslexia is the most common learning disability (Rief\&Stern, 3).

According to the International Dyslexia Association (2002), dyslexia is a specific learning difficulty, with a neurobiological origin characterized with difficulties that occur in the accurate and fluent recognition of words, which are manifested by spelling problems and problems with the abilities for decoding.

During the reading process, our eyes scan over the printed text in a series of fast movements called saccades. These movements are intersected with short fixation periods, when the eyes stop at a part of the text, and during the fixation, we actually process the text (Stark et al., 1991). Every fixation lasts for around 250 milliseconds, although this period of time could be shorter or longer depending on the nature and complexity of the text. Usually, we scroll through known words and functional words, and on the other hand we also have a tendency to fixate on long and unknown words. The fixation duration is also under the influence of the ease with which we are capable of processing the text. Good readers generally move their eyes forwards (left to right or right to left, depending on the language) while the dyslexic, bad or unexperienced readers spend more time looking backwards towards previously read words, producing regressive saccades in that manner. These more frequent fixations also last longer (Kaровска Ристовска et al., 2016).

Having in mind that reading and writing are extremely important for success in and out of school, dyslexic students face the risk of academic failure, and a lower reading efficiency and self-correction (Burden, 2008), as well as a lower self-esteem (Alexander-Passe, 2006). One group of dyslexic readers shows difficulties in the letter and word reversibility, or in the mixing of similar letters or words. Children with good visual perception skills experience less problems in the identification of the letter shapes, while children with poorer visual skills have problems with the letter perception and they will most likely face difficulties in the learning of reading. Dyslexic readers compared to non-dyslexic readers are weaker in: reproduction (extracting) complex visual figures from the memory; mental rotation of letters and objects; and identification of elements missing in a picture (for example: a door that is missing a handle). They 
also need more time to name the pictures with everyday objects, like: chalkboards, car or a window. Dyslexic readers compared to non-dyslexic readers are also slower than the non-dyslexic readers during a task performance in which they need to analyze a rapidly represented visual information. For the dyslexic readers, the symbol needs to be visible for a longer time so that they can locate it on the picture, especially if it is surrounded with similar symbols-distractors. The presence of abnormal cells in the visual system and the visual perception problems that they cause might explain why the printed text looks blurry and moves off the page in dyslexic children.

\section{Comparative analysis of researches related to dyslexia fonts}

Having in mind that around $10 \%$ of the population is dyslexic, text presentation has a significant effect on their reading ability. Four decades of researches about dyslexia suggest that the reading difficulties originate from the basic deficits in the alphabetic and phonological coding rather than the visual, semantic or syntax deficits (Vellutino et al., 2004). Still, the use of specially designed fonts shows that in a certain percentage of the persons with dyslexia, especially the ones that face orthographic dyslexia, they improve the text readability, as well as the reading speed.

Although research most often shows the link between the phonological skills and reading, a certain number of researches point to the relation between the reading and seeing skills (Lovegrove, Martin \& Slaghuis, 1986; Irlen \& Glass, 1989). The magnocellular theory of dyslexia supports the idea of a link between the visual problem and reading (Stein \& Walsh, 1997). During reading, the visual sensitivity is not suppressed enough by the magnocellular system, so fixations from one place to another in the text cannot be differentiated.

Nevertheless, there are few studies that objectively measure the influence of the font type on reading. One of them is the study conducted by Reelo and Baeza-Yates (2013), which shows that the font type in which the digital text is printed has a significant influence on the text readability when it comes to persons with dyslexia. According to these authors, the fonts that are appropriate for dyslexia are: Helvetica, Courier, Ariel, Verdana and Computer Modern Unicode. Arial It should be avoided because it reduces readability. Sans Serif improves reading in dyslexic readers. The authors Bachmann and Mengheri (2018) prove that the specially developed font EasyReading can be used as a compensation tool in persons with dyslexia, but also in all categories of readers.

On the one hand, de Leeuw (2010) in her master thesis, using the fonts Ariel and Dyslexie for exploring text readability, suggests that they didn't lead to faster reading, but they do contribute to the reduction of mistakes caused by dyslexia. On the other hand, the research of Wery and Diliberto (2017) that used the Open Dyslexic font in comparison to the Times New Roman and Ariel fonts for assessment of the speed and accuracy of the reading in children with dyslexia established that there is no improvement in the reading in dyslexic individuals. 


\section{Features of dyslexia fonts}

The readability of a text depends on a large number of the features of the font in which the text is written. The features are always interrelated and generally, they include: character size, space between the characters and rows and shape of the font $(\mathrm{Ku}-$ ster, van Weerdenburg, Gompel and Bosman, 2018). Research shows that the fonts with bigger size are much more easily readable (Perea, Panadero, Moret-Tatay \& Gómez, 2012). During the creation of the font size, which basically entails character size, the typographers determine the lowest and highest point of the character, thus adding minimal additional space, but enough so that letters don't touch one another (Legge \& Bigelow, 2011; Spelbrink, 2012). This additional space enables letters to be visually separated from one another.

According to the listed features of reading in persons with dyslexia and manipulation with the basic typographic parameters, there is an opportunity for creation of fonts adjusted to the needs of these persons. Several such fonts have been created (Sylexiad, Dyslexie, Read Regular and Open Dyslexic), which basically have a larger differentiation of the characters than the existing ones. What is common for all of them, and what the creators found out, is that size does matter. Hence, the characters in these fonts are larger than the standard ones (Table 1).

Table 1.

\begin{tabular}{|c|c|}
\hline Font & Example \\
\hline Times New Roman & dyslexia. \\
\hline Arial & dyslexia. \\
\hline Open Dyslexic & dyslexia. \\
\hline Dislexie & dyslexia. \\
\hline Sylexiad & dyslexia \\
\hline
\end{tabular}

O'Brien, Mansfield and Legge (2005) pointed out that, unlike the typically developed children, when it comes to reading skills, children with dyslexia need a larger size of the letters so that they can achieve a greater reading speed. The significance of the size of the characters is pointed out by the series of experiments conducted by Wilkins and associates (Hughes \& Wilkins, 2000; Wilkins, Cleave, Grayson, \& Wilson, 2009; Wilkins, et al., 2007), which proved that children generally have a larger benefit from bigger sized characters during the reading tasks they were given.

Another feature of the fonts for dyslexic persons is the increased space between the letters. Many authors suggest that the increase of the space between the letters 
is meaningful for the reading process in dyslexic persons (Perea et al., 2012; Zorzi et al., 2012). Considering the characters have a larger size and the additional space between them is increased, this leads to the avoiding of letter fusion. Instead of the minimal separation space, the additional space surrounding the characters is expanded in the specially created fonts for dyslexic persons.

Every font has a unique shape. As one of the above mentioned features, shape, along with characters size and the space between them, is a parameter that makes one font different from the others. As Kuster and his associates (2018) point out, the font's shape depends of the thickness, the contrast and whether the fonts are Serif or Sans Serif. Regarding the thickness parameter, it is characteristic that in part of the fonts created for persons with dyslexia, there is a unique thickening in the base of the characters (Open Dyslexic and Dyslexie). The purpose of the introduction of this parameter is to enable an easier tracking of the rows in up-down direction. The contrast regards the relation between the thinner and thicker parts of the characters. In dyslexia fonts, the contrast becomes larger with the thickening of certain parts of the characters.

A widely discussed parameter related to the readability of the fonts for persons with dyslexia is the presence of Serif. Serif is an addition (additional horizontal and vertical lines) at the ends of the basic letter (de Leeuw, 2010). The font used for writing this text, Times New Roman, is an example of a Serif font. Many authors believe that the serifs give an additional load to the text, especially in persons with dyslexia. As Wilkins and his associates (2007) point out, the Serif is a factor for visual noise to the reader of the text. Although there is data to support the theory that the degree of readability of the Sans Serif fonts is larger than the one of the Serif fonts (Woods, Davis, \& Scharff, 2005), the data from the research of Arditi and Cho (2005) suggest the contrary. Nevertheless, all fonts for dyslexia created so far are Sans Serif, according to the recommendation of the British Dyslexia Association (2014).

From all existing fonts for dyslexia, only Dyslexie has additional features. Besides all the parameters stated above, this font is characterized by a thickening of the capital letter. Having in mind that persons with dyslexia have difficulties in following punctuation signs (Каровска Ристовска, Кардалеска и Ајдински, 2016), the thicker саpital letter will mean an easier orientation in the text for the beginning of new sentences, as well as words that signify names.

\section{Cyrillic font for dyslexia}

All of the above-mentioned fonts for persons with dyslexia are made in Latin scripts, meaning that the countries that use Cyrillic scripts, including Republic of Macedonia, cannot use the existing fonts. Bearing this fact in mind, recently, members of the Faculty of Philosophy in Skopje created the first Cyrillic font for persons with dyslexia. The font named Dyslexic FZF, based on the Latin font Open Dyslexic, contains the main features owned by the larger number of persons with dyslexia. It is a Sans Serif 
font with specifically produced Macedonian alphabet letters, numerical and punctuateon signs.

The main feature of the font is the thickening of the base of each character, the increased size of the characters and the increased spacing. Having in mind that there is a highlighted ratio of the thicker and thinner parts, the font has a more prominent contrast. All these features can be seen in Table 2. The Dyslexic FZF font is set in comparison with the Times New Roman font, as a Serif font and the Arial font as a Sans Serif font. There is a perceptible difference between the size of the signs, the contrast, the space between the characters and the rows (single in the table).

Table 2.

\begin{tabular}{c|c} 
Times New Roman & $\begin{array}{c}\text { Cyrillic font for persons with dyslexia. The font has a spe- } \\
\text { cific shape. }\end{array}$ \\
\hline Dyslexic FZF & $\begin{array}{r}\text { Cyrillic font for persons with dyslexia. } \\
\text { The font has a specific shape. }\end{array}$ \\
\hline Arial & $\begin{array}{c}\text { Cyrillic font for persons with dyslexia. The font has a } \\
\text { specific shape. }\end{array}$
\end{tabular}

Dyslexic FZF, just like Dyslexie, features a certain tilting of the vertical and horizontal basic lines of the letter, as well as increased openings of the alphabetic signs such as e, $\mathrm{s}$ and a. One feature that the new Cyrillic font does not have is a thickening of the capital letters in the text, but it does make a distinction between the alphabetic and numerical signs. The numbers have a bigger size so that they can be easily separated in the text.

\section{Conclusion}

The existence of different theories for dyslexia points to the existing of different types of dyslexia. The phonological deficit theory suggests that dyslexia develops because of a problem in the phonological processing and the inability to link graphemes to phonemes. The visual theory represents the traditional view of dyslexia in a manner that the visual problem creates issues in the processing of information from letters and words to written text (Ramus et al., 2003). The cerebellar theory (Stoodley\&Stein, 2009) suggests that the dysfunctional cerebellum can cause dyslexia, or that the damage in the decoding of signals from cerebellar origin influences the brain's processing. The fast auditory processing theory is an alternative of the phonological theory and according to it, the primary deficit lies in the perception of short or fast-variable sounds (Ramus et al., 2003). The magnocellular theory makes an effort to unify the cerebellar theory, the phonological theory, the fast auditory theory and the visual theory. It suggests 
that the magnocellular dysfunction is not limited only to the visual pathways, but it also includes the auditory and tactile modalities (Ray et al., 2005).

The large number of theories about the origin of dyslexia show that not all dyslexic readers manifest identical symptomatology when reading. Because of that, many different work strategies do not benefit all dyslexic readers identically. One of the strategies, when it comes to written electronic text, is the creation of special fonts for dyslexia. All existing fonts are created based on the difficulties that dyslexic readers face and they are incorporated in the shape of the characters, the size and the space between them. Taking the magnocellular theory and the orthographic dyslexia into consideration, the fonts created for dyslexic readers can produce results in reading alleviateon. Nevertheless, the success of the fonts for dyslexia depends on the dyslexia type, and the largest benefit will be found in persons that face visual discomfort and binocular instability during reading. 


\section{References}

Alexander-Passe, N. (2006). How dyslexic teenagers cope: an investigation of self-esteem, coping and depression. Dyslexia, 12, 256-275.

Arditi, A., \& Cho, J. (2005). Serifs and font legibility. Vision Research, 45(23), 2926-2933.

Bachmann, C., \& Mengheri, L. (2018). Dyslexia and Fonts: Is a Specific Font Useful? Brain Sciences, 8(5).

British Dyslexia Association (2014). Dyslexia style guide. Retrieved on May 2, 2018 from http://www.bdadyslexia.org.uk/about-dyslexia/further-information/dyslexia-style-guide.html

Burden, R. (2008). Is dyslexia necessarily associated with negative feelings of selfworth? A review and implications for future research. Dyslexia, 14(3), 188-196.

de Leeuw, R. (2010). Special Font for Dyslexia? [Unpublished Master's thesis]. University of Twente, the Netherlands.

Zorzi, M., Barbiero, C., Facoettia, A., Lonciari, I., Carrozzi, M., Montico, M., ..., Pech-Georgel C., \& Ziegler, J. C. (2012). Extra-large letter spacing improves reading in dyslexia. Proceedings of the National Academy of Sciences of the United States of America, 109, 11455-11459.

Hughes, L., \& Wilkins, A. (2000). Typography in children's reading schemes may be suboptimal: evidence from measures of reading rate. Journal of Research in Reading, 23(3), 314-324.

International Dyslexia Association. (2008). Just the facts: Definition of dyslexia. Retrieved July 3, 2009, from www.interdys.org/ewebeditpro5/upload/Defi nition_Fact_ Sheet_3 -10 - 08.pdf

Irlen, H., \& Lass, M. J. (1989). Improving reading problems due to symptoms of scotopic sensitivity syndrome using Irlen lenses and overlays. Education, 109, 413-417.

Karovska Ristovska, A., Kardaleska, Lj., Ajdinski, G. (2016). Сйецифични иеешкойии во учењейо (gислексија, gисірафија, gискалкулија и gисйраксија). Скопје: Филозофски факултет.

Kuster, S.M., van Weerdenburg, M., Gompel, M. \& Bosman, A.M.T. (2018). Dyslexie font does not benefit reading in children with or without dyslexia. Annals of Dyslexia, 68(1), 25-42.

Legge, G. E., \& Bigelow, C. A. (2011). Does print size matter for reading? A review of findings from vision science and typography. Journal of Vision, 11(5), 1-22.

Lovegrove, W., Martin, F., \& Slaghuis, W. (1986). The theoretical and experimental case for a visual deficit in specific reading disability. Cognitive Neuropsychology, 3, 225-267.

O'Brien, B. A., Mansfield, J. S., \& Legge, G. E. (2005). The effect of print size on reading speed in dyslexia. Journal of Research in Reading, 28, 332-349. 
Perea, M., Panadero, V., Moret-Tatay, C., \& Gómez, P. (2012). The effects of inter-letter spacing in visual-word recognition: Evidence with young normal readers and developmental dyslexics. Learning and Instruction, 22, 420-430.

Ramus, F., Rosen, S., Dakin, S.C. (2003). Theories of developmental dyslexia: insights from a multiple case study of dyslexic adults. Brain. 126 (4), 841-65.

Rello, L., Baeza-Yates, R. (2013). Good Fonts for Dyslexia. Proceedings of the 15th International ACM Sigaccess Conference on Computers and Accessibility. Bellevue-Washington October 21-23, 2013.

Ray, N.J., Fowler, S., Stein, J.F. (2005). Yellow filters can improve magnocellular function: motion sensitivity, convergence, accommodation, and reading. Ann. N. Y. Acad. Sci. 1039, 283-93.

Rief, S., Stern, S. (2010). The Dyslexia Checklist. San Francisco: Jossey-Bass.

Spelbrink, N. (2012). Framing fonts. Eindhoven, the Netherlands: Lecturis publishing.

Stark, L. W., Giveen, S. C., \& Terdiman, J. F. (1991). Specific dyslexia and eye movements. In J. Cronly-Dillon (Ed.), Vision and visual dysfunction (Vol. 13, pp. 202-232). London: Macmillan.

Stoodley, C.J., Stein, J.F. (2009). "The cerebellum and dyslexia". Cortex. 47 (1), 101-16

Stein, J., \& Walsh, V. (1997). To see but not to read; the magnocellular theory of dyslexia. Trends in Neurosciences, 20, 147-152.

Vellutino, F. R., Fletcher, J. M., Snowling, M. J., \& Scanlon, D. M. (2004). Specific reading disability (dyslexia): what have we learned in the past four decades? Journal of Child Psychology and Psychiatry, 45(1), 2-40.

Wery, J.J. \& Diliberto, J.A. Ann. of Dyslexia (2017) 67: 114

Westwood, P. (2008). What teachers need to know about reading and writing difficulties. Camberwell: ACER Press.

Wilkins, A., Cleave, R., Grayson, N., \& Wilson, L. (2009). Typography for Children May Be Inappropriately Designed. Journal of Research in Reading, 32(4), 11.

Wilkins, A., Smith, J., Willison, C., Beare, T., Boyd, A., Hardy, G., et al. (2007). Stripes within words affect reading. Perception, 36, 1788-1803.

Woods, R., Davis, K., \& Scharff, L. (2005). Effects of Typeface and Font Size on Legibility for Children. American Journal of Psychological Research, 1(1), 86-102. 